\title{
1. VALORES Y PRINCIPIOS CONSTITUCIONALES
}

\author{
PREÁMBULO, PRECEPTOS DEL TÍTULO PRELIMINAR \\ Y ARTÍCULO 10.1
}

\author{
ANTONIO TORRES DEL MORAL \\ Catedrático de Derecho Constitucional \\ UNED
}




\section{SUMARIO}

I. Preámbulo y artículos 1.1 y 10.1: Valores Y principios.-II. Articulo 1.2: La soberania.-III. Artículo 1.3: La Monarouía parlamentaRIA.-IV. ARTículo 2. : UNIDAD INDISOLUble Y DERECHO A LA AUTONOmía.-V. Artículos $3 .^{\circ}$ y $4 .^{\circ}:$ PluRalismo lingüístico Y Simbólico.VI. Articulo 9.': El Estado de Derecho. 6.7. Constitución normativa. 6.2. Estado social. 6.3. La seguridad jurídica. 


\title{
1. VALORES Y PRINCIPIOS CONSTITUCIONALES
}

\author{
PREÁMBULO, PRECEPTOS DEL TÍTULO PRELIMINAR Y ARTÍCULO 10.1
}

POR

ANTONIO TORRES DEL MORAL

Catedrático de Derecho Constitucional

UNED

\section{PREÁMBULO Y ARTÍCULOS 1.1 Y 10.1: VALORES Y PRINCIPIOS}

El Preámbulo de la Constitucion es una pieza breve y equilibrada. Muy poco conocido salvo entre expertos, su carencia de valor normativo puede sugerirnos la innecesariedad de su reforma. No obstante, su posible y plausible utilización como elemento de interpretación de la Constitución nos persuade de la conveniencia de introducir en él algún retoque.

Concretamente, su primer párrafo menciona como fines o anhelos de la nación española la justicia, la libertad y la seguridad. Nada habría que oponer, en principio. Pero parece oportuno conciliar lo proclamado en el Preámbulo con lo propugnado en el artículo 1.1.

Ahora bien, en esta operación de ajuste de los textos relativos a valores y principios fundamentales, debe tenerse en cuenta igualmente la dignidad de la persona, desplazada actualmente al artículo 10.1. A mi juicio, la dignidad de la persona tiene más contenido axiológico que el pluralismo político, que es un mero resultado - muy valioso como tal, eso side la libertad. Más aún: es resultado de la libertad en un determinado ámbito de la vida humana: el político. ¿Puede sostenerse acaso que el pluralismo político debe informar el Ordenamiento en materia de derechos reales o de letra de cambio? 
De otro lado, como ha puesto de relieve un sector de la doctrina, la justicia y la igualdad son valores coextensivos si se los interpreta cabalmente, de manera que bien podría reducirse la mención de los dos a uno solo.

Hay, sin embargo, una fuerte contraindicación a la alteración de la literalidad - pues su espíritu queda intacto- del artículo 1.1, verdadero precepto insignia de la Constitución y del régimen que instaura. Es tal su grado de aceptación en medios políticos y sociales que forma parte ya de la cultura juridica y política española.

Aun asi, nada obsta a que una nueva redacción, más sencilla y técnicamente más correcta, logre igual grado de consenso.

Puestos a ello, es difícil preferir entre la igualdad y la justicia para que figuren en los mencionados textos sin reduplicarse entre sí. Acaso convenga utilizar las dos expresiones, cada una en un lugar. En este orden de consideraciones, el carácter más preciso que ha adquirido la igualdad en nuestro Ordenamiento jurídico gracias a la dilatada jurisprudencia del Tribunal Constitucional, hace preferible su inserción en el articulado, pudiendo quedar la justicia en el Preámbulo, tal y como figura en su redacción actual.

En resumen, se propone:

a) Incluir la dignidad de la persona entre los valores superiores del Ordenamiento jurídico, excluyéndola, en consecuencia, del artículo 10.1.

b) Suprimir, por razones muy diferentes, las menciones del pluralismo político y de la justicia.

El párrafo cuarto del Preámbulo es también susceptible de retoques. Efectivamente, es dudoso que los pueblos sean sujetos de derechos en el sentido técnico-jurídico de la palabra. De otro lado, es evidente que la Constitución reconoce y garantiza los derechos humanos de todas las personas y no sólo de los españoles, aunque haya diferencias justificadas y así debe decirlo el Preámbulo.

En otro orden de ideas, la cuidada redacción del Preámbulo ha buscado evitar la repetición de los verbos con los que inicia cada párrafo. Cosa diferente es que haya adjudicado a cada meta política el verbo más adecuado.

Así, por ejemplo, la sociedad democrática avanzada no es algo que 
pueda establecerse y quedar establecido sino que se aspira a ella y a duras penas se alcanza. A fines de 1978 ya se vivía democráticamente en España; por eso era mejor decir que la nación española aspiraba a consolidarla. En cambio, el Ordenamiento jurídico estaba en vías de un cambio radical, precisamente por obra de la Constitución; era preferible, entonces, proclamar la voluntad española de establecer un Estado de Derecho que la de consolidarlo, puesto que apenas existía.

En fin, el artículo 10.1, ya sin la mención de la dignidad humana, puede ser aligerado todavía más. De un lado, la calificación que hace de los derechos como inherentes es, cuanto menos, discutible. De otro lado, que los conceptos incluidos en este precepto sean fundamento del orden político y los del artículo 1.1 sean valores del Ordenamiento jurídico es algo sencillamente ininteligible; el hecho de que el artículo 10 encabece el título correspondiente a los derechos habla bien claro de que el constituyente lo erigió en fundamento de este título, y así debe decirlo. Por último, la alusión a la paz social no añade nada en el hipotético caso de que alguien sepa en qué consiste. cionados:

En conclusión, se propone la siguiente redacción de los textos men-

PREÁMBULO:

Párrafo primero: "La nación española, deseando promover la justicia, la libertad, la dignidad humana y el bien de cuantos la integran, en uso de su soberanía, proclama su voluntad de:

Párrafo segundo: "Consolidar...»

Párrafo tercero: "Establecer...»

Párrafo cuarto: "Garantizar los derechos humanos y proteger las culturas, las tradiciones, las lenguas y las instituciones de todos los pueblos de España».

Párrafo sexto: "Alcanzar..."

Artículo 1.1: «España se constituye en un Estado social y democrático de Derecho que propugna como valores superiores de su Ordenamiento jurídico la libertad, la igualdad y la dignidad de la persona".

Artículo 10.7: "Los derechos inviolables de la persona, el libre desarrollo de la personalidad, el respeto a la ley y a los derechos de los demás son fundamento de este títulon. 


\section{ARTÍCULO 1.2: LA SOBERANÍA}

La dicción literal de este precepto ha sido objeto de muchas críticas, excesivas a mi parecerer y no del todo justificadas.

Es posible que el constituyente español, como en 1958 el francés, haya querido fundir - confundir no creo- los conceptos de soberania popular y nacional, en torno a los cuales se han alineado, con más voluntad que acierto, las izquierdas $y$ las derechas europeas. Lo infundado de las mencionadas correlaciones han sido objeto de atención por mi parte en algunos escritos. A ellos remito.

Hoy - al menos, hoy - en un Estado social y democrático de Derecho, con sufragio universal (activo y pasivo; masculino y femenino), libre, igual, directo y secreto, la soberanía popular y la nacional son una y la misma cosa. Así, pues, bien está como está el precepto que comentamos, aunque acaso sería mejor eliminar de una vez la soterrada ambigüedad y decir sencillamente:

"La soberanía reside en el pueblo español, del que emanan todos los poderes del Estado".

La inclusión del adjetivo todos para referirlo a los poderes del Estado es seguramente innecesaria, pero no inconveniente como simple refuerzo de la idea del constituyente.

\section{ARTÍCULO 1.3: LA MONARQUÍA PARLAMENTARIA}

También ha sido criticado, con desigual tino, este precepto. A mi juicio no se confunden en él la forma de Estado con la forma de gobierno. Tampoco se entiende bien que la Monarquía sea forma política del Estado y la Monarquía parlamentaria sea la forma jurídica de gobierno, como ha sostenido un sector de la doctrina. Todas las formas que adopta un Estado o su gobernación son formas políticas y todas ellas, en un Estado de Derecho, han de producirse jurídicamente.

El precepto comentado expresa sintéticamente dos formas políticas que adopta el Estado español: la forma monárquica de la Jefatura del Estado y el sistema parlamentario de gobierno. 
La única reserva que merece el precepto es el uso del artículo determinado la, que parece indicar que estamos ante la única forma -política y jurídica- del Estado español, siendo así que también lo son la organización territorial autonómica y su configuración como Estado social y democrático de Derecho.

Lo difícil es sustituir la fórmula acuñada por otra más precisa. «EI Estado español se constituye como Monarquía parlamentaria» tiene el inconveniente de repetir la expresión utilizada - "se constituye" - por el artículo 1.1. Su sustitución por "se configura" le resta precisión. Es, pues, preferible la fórmula más breve y sencilla:

«El Estado español es una Monarquía parlamentaria»

que dice bien lo que quiere decir y no niega que el Estado español reviste, además, otras formas.

\section{ARTÍCULO 2. : UNIDAD INDISOLUBLE Y DERECHO A LA AUTONOMÍA}

Sobre este artículo se ha teorizado tanto que apenas queda nada por decir. Tampoco lo pretendo en esta ocasión. Repararemos tan sólo en dos palabras que podrían parecernos sustituibles por otras más ajustadas. Son indisoluble $y$ derecho.

a) En un principio se interpretó como un desliz del constituyente el hablar de indisoluble unidad de la nación española. Acaso un prurito literario le hizo utilizar este término por no repetir dos veces indivisible en el mismo precepto.

Al cabo del tiempo ha resultado un acierto. La desaparición de la URSS ha puesto de relieve que una cosa es la división de un Estado y otra su disolución. La URSS no se ha dividido: se ha disuelto. Así, pues, el término indisoluble ha resultado ser mucho más preciso de lo que acaso pretendió el constituyente.

b) Por lo que a la segunda locución se refiere, adelantaré que entiendo que la constitución de las Comunidades Autónomas por parte de las nacionalidades $y$ regiones es una opción política que pudieron ejercer 
ciertos entes públicos territoriales, a la cual sólo en sentido analógico puede denominársela derecho. Con todo, creo que no ha dado lugar a interpretaciones desviadas y el hecho de estar ya consumado el proceso de constitución de las Comunidades Autónomas minimiza el problema, por lo que vale más dejar la literalidad actual del precepto.

\section{ARTICULOS $3 .^{\circ}$ Y $4 .^{\circ}$ : PLURALISMO LINGÜISTICO Y SIMBÓLICO}

El apartado primero puede comenzar diciendo:

"El castellano es la lengua oficial del Estado",

sin necesidad de aclarar que se trata de una lengua española, adición completamente ociosa y literariamente infame.

El resto del apartado, así como el apartado segundo, no ofrecen flanco a la reforma. En cambio, el tercero es una reduplicación de lo que se establece de modo más completo en el artículo 46.

Anticipar al título preliminar, como principio fundamental, un aspecto del patrimonio cultural, cual es la diversidad lingüistica española, por importante que ésta sea, no regula mejor la materia ni compromete más a los poderes públicos. Es comprensible que en 1978 pareciera conveniente al constituyente compensar la declaración de oficialidad estatal del castellano con dos apartados referidos a "las demás» lenguas. Es dudoso que actualmente el comentado apartado tercero rinda tan prudente servicio, pero suprimirlo seguramente crearía más problemas de los que pudiera resolver.

En cuanto al artículo $4 .^{\circ}$, solamente una precisión merece ser hecha: debe iniciarse el apartado segundo con la expresión:

"Los Estatutos de autonomía»,

que es más precisa que la de los Estatutos a secas.

El artículo $5 .^{\circ}$ no es susceptible de matiz o mejora. Los artículos $6 .^{\circ}$ y $7 .^{\circ}$ son examinados en una ponencia específica de este Congreso, a la que remito. Lo mismo cabe decir del artículo $8 .^{\circ}$ 


\section{ARTICULO 9.: EL ESTADO DE DERECHO}

El artículo $9 .^{\circ}$ es uno de los más complejos y completos de la Constitución. Sus tres apartados componen casi un tratado sobre el Estado de Derecho: Constitución normativa, Estado social y principios de seguridad jurídica. Los dos primeros apartados son otros tantos preceptos insignias del texto fundamental.

\subsection{Constitución normativa}

A mi juicio, en el apartado primero tan sólo convendría reforzar la idea de superioridad jerárquica de la Constitución, que en su redacción actual necesita ser deducida de su literalidad y de su relación con los títuIos IX y X. Bastaría para ello una breve adición tras la palabra Constitución:

"Los ciudadanos y los poderes públicos están sujetos a la Constitución, como norma suprema, $y$ al resto del ordenamiento jurídico».

\subsection{Estado social}

Aunque no ha sido utilizado, ni parece que vaya a serlo, como palanca de cambio social, la redacción de este precepto, tan citado, supera la de su correlativo artículo 3.2. de la Constitución italiana. A mi juicio no es mejorable más que sustituyendo el singular individuo por el plural, con la correspondiente concordancia verbal. Lo propongo así porque el singular individuo resulta muy abstracto frente a los plurales grupos y ciudadanos que emplea el mismo precepto.

Con esta leve corrección, el texto quedaría así:

"Corresponde a los poderes públicos promover las condiciones para que la libertad y la igualdad de los individuos y de los grupos en que se integran sean reales y efectivas; remover los obstáculos que impidan o dificulten su plenitud y facilitar la participación de todos los ciudadanos en la vida política, económica, cultural y social».

\subsection{La seguridad jurídica}

La doctrina apenas ha reparado en el deficiente tratamiento de la seguridad jurídica en este precepto. Ha llamado más la atención el elenco 
de principios consagrados en él, los cuales, en su conjunto, significan el Estado de Derecho puesto en práctica.

Ello es justo, pero también que todos los principios son expresiones parciales del de seguridad jurídica o, formulado por el envés, que todos ellos son factores que contribuyen a la consecución de una más plena seguridad jurídica. Éste es, pues, un concepto más amplio $y$, como tal, más expresivo de la idea de juridicidad estatal y así debe ser destacado. Sugiero, pues, adelantar y destacar la mención de la seguridad jurídica al comienzo del precepto.

En segundo lugar, debe precisarse la idea de que la irretroactividad se predica de las normas desfavorables, no de la meramente no favorables. Ese es el espíritu constitucional.

Por último, la redacción de los dos últimos principios debe ser variada para su más correcta expresión, puesto que la fórmula actual obliga a interpretar que la responsabilidad de que habla es la de los poderes públicos.

En consecuencia, el precepto quedaría de la forma que sigue:

"La Constitución, para la más plena consecución de la seguridad jurídica, garantiza el principio de legalidad, la jerarquía normativa, la publicidad de las normas, la irretroactividad de las disposiciones sancionadoras desfavorables o restrictivas de derechos individuales, la responsabilidad de los poderes públicos y la interdicción de su arbitrariedadn. 